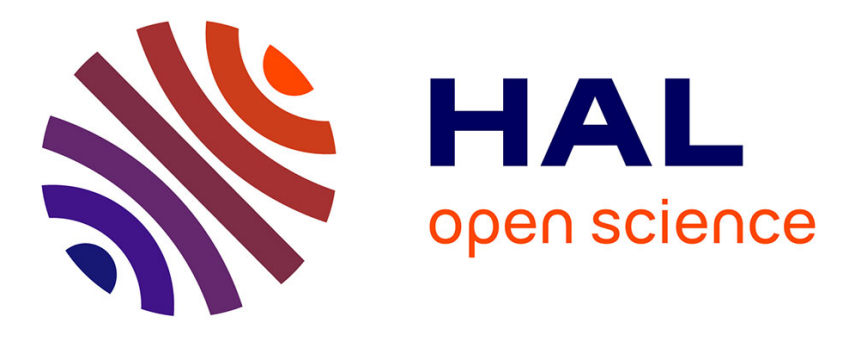

\title{
Sharing Economy Digital Platforms and Social Inclusion/Exclusion: A Research Study of Uber and Careem in Pakistan
}

Fareesa Malik, Zujaja Wahaj

\section{- To cite this version:}

Fareesa Malik, Zujaja Wahaj. Sharing Economy Digital Platforms and Social Inclusion/Exclusion: A Research Study of Uber and Careem in Pakistan. 15th International Conference on Social Implications of Computers in Developing Countries (ICT4D), May 2019, Dar es Salaam, Tanzania. pp.248-259, 10.1007/978-3-030-18400-1_20. hal-02285288

\section{HAL Id: hal-02285288 \\ https://hal.inria.fr/hal-02285288}

Submitted on 12 Sep 2019

HAL is a multi-disciplinary open access archive for the deposit and dissemination of scientific research documents, whether they are published or not. The documents may come from teaching and research institutions in France or abroad, or from public or private research centers.
L'archive ouverte pluridisciplinaire HAL, est destinée au dépôt et à la diffusion de documents scientifiques de niveau recherche, publiés ou non, émanant des établissements d'enseignement et de recherche français ou étrangers, des laboratoires publics ou privés.

\section{(ㄷ)(i)}

Distributed under a Creative Commons Attribution| 4.0 International License 


\title{
Sharing Economy Digital Platforms and Social Inclusion/ Exclusion: A Research Study of Uber and Careem in Pakistan
}

\author{
Fareesa Malik $^{1}$ (ORCID 0000-0002-1926-8408) and Zujaja Wahaj ${ }^{2}$ \\ ${ }^{1}$ NUST Business School, National University of Science and Technology, Islamabad, Pakistan \\ fareesa.malik@nbs.nust.edu.pk \\ ${ }^{2}$ NUST Business School, National University of Science and Technology, Islamabad, Pakistan \\ zujaja.wahaj@nbs.nust.edu.pk
}

\begin{abstract}
The sharing economy business models enabled by digital platforms are shifting the landscape of economic growth and nature of employment globally. This study focuses on digital travel industry of Pakistan and aims to explore the social and economic implications of sharing economy platforms. Drawing on the concepts of social inclusion/exclusion from ICT and IS literature, we examine the potential participation of digital platforms in social inclusion/ exclusion of the society. We adopted an interpretive and qualitative research design. The data was collected through informal talks, observations and semi-structured interviews. For our research study, we selected two online ride-hailing companies operational in Pakistan, Uber and Careem. The study shows social impacts of sharing economy digital-platforms to enhance culture of trust, family confidence and women empowerment. It highlights the inclusion of unemployed groups through self-entrepreneurship that improve economic activities in the society. The study also identifies few contradictions and potential challenges that support social exclusion due to technology, such as biased gendered contribution in economic activities, generation/age constraints in usability and accessibility issues based on geographic locations.
\end{abstract}

Keywords: Sharing Economy . Digital Platforms . Uber/Careem . Social

Inclusion/exclusion . ICT4D

\section{Introduction}

The recent decade witnesses a massive emergence of digital platform based businesses that have become household names in short span of time, such as Uber, Airbnb, Lyft, YouTube and Upwork. These platform based digital businesses are rooted in the concept of collaborative consumption enabled by "activities of sharing, exchanging and rental of resources without owning the goods" [26, pp. 143]. In management literature, different labels exist for the phenomenon of using and sharing of product and services (e.g. gig economy, collaborative consumption, peer-to- peer economy, sharing economy). The term "sharing economy", coined in 2008, captures the whole ecosystem including economic and market arrangements related to this collaborative consumption phenomenon [26, 34, 37]. The sharing economy is defined as collaborative economy and collaborative consumption to exchange underused or unwanted assets for income generation [5]. The phenomenon of resource sharing is not new to our society. Humans are accustomed to sharing extra resources, such as room, time, vehicles, and other consumable goods with people they know (e.g. relatives, friends, and neighbours). However, the business model of "sharing 
economy" extends the resource sharing to strangers to generate income. The resource sharing perspective does not only optimise the use of resources by utilising the idle resources but also enhances social and economic activities in the society, particularly in developing countries, where resources are not easily accessible and affordable to everyone. This study explores the potential social and economic implications of sharing economy in developing countries. It also examines how online digital platforms affect social inclusion/exclusion in the society.

Unlike traditional markets that are based on owing goods, sharing economy emphasises on social value in parallel with financial value to build stronger communities through resource sharing. It has emerged from niches to profitable markets and attracted millions of users and business investment [30]. The sharing economy sector is estimated to generate revenue of approximately $\$ 335$ billion by 2025 [35]. This tremendous growth potential of sharing economy sector may pose a serious threat to traditional industries, especially retail, hospitality, technology, media, entertainment, and travel [20].

Sharing economy has already attracted management scholars' attention. However, because of an emerging domain, the research is still in infancy. Responding to the research need to strengthen the theoretical understanding of this emerging research area, we study a sharing economy phenomenon in travel industry of Pakistan. In this article, we aim to explore:

1- How online ride-hailing companies are transforming the existing social and economic structures? and

2- How can sharing economy contribute in social inclusion/exclusion in the society?

To find answers to these research questions, we conducted an interpretive and qualitative field study in Pakistan from February to September, 2018. For data collection, we selected two online ride-hailing platform based companies operational in Pakistan: Uber and Careem. We consulted ICT and information systems literature of social inclusion/exclusion that guided our research enquiry [48, 49, 50]. The article identifies that technology-enabled sharing economy platforms may act as catalyst to change the social and economic dynamics of the society by supporting social inclusion of the disadvantaged groups e.g. unemployed, women, low income group and socially isolated. It also explores the other side of the coin and provides counter arguments to highlight barriers that sharing economy may bring to increase social exclusion based on gender, age, and geographic location [3].

\section{Literature Review}

\subsection{Sharing Economy and its Societal Implications}

Along with enormous potential to transform traditional industries, sharing economy provides social and economic benefits to individuals and societies through its advanced digital technologies, convenience model, cost saving, environmental sustainability, new consumption patterns and social interaction [18, 24]. It enables 
higher levels of economic activities by creating markets that support exchange of goods and services and open opportunities for maximum utilization of assets and skills [4]. The sharing economy supports crowd-based networks that encourage supply of labour from decentralized individuals' crowd rather than corporations [37, 46]. The sharing of resources is enabled via community based online platforms that facilitate the interaction between producers and consumers. These online platforms also provide trust mechanisms that are enabled through screening of individuals, feedback loops and secure payment options [5, 12, 17]. The platforms define polices and governance rules; thus, act as regulatory bodies to ensure smooth transaction of exchange through the platform. In return, these digital platforms keep slice of the financial transaction of each successful exchange[33].

The existing research studies attempt to explore the opportunities and challenges that sharing economy offer to the society [16]. The economic impacts of sharing economies have been discussed in literature as cost saving through utility maximization behaviour by providing short-term access to resources that stand idle otherwise [17, 25, 31]. The sharing economy platforms attract users' participation by providing lower price services as compared to their traditional counterpart. The studies discuss the relationship between economic advantage and number of users on the platform [17]. The significant reasons of users' participation in sharing economy are availability, convenience, monetary savings and expanded mobility [4, 17]. The literature has been classified into two streams: individual level studies that identify the intrinsic and extrinsic benefits of the users' participation; and organizational level studies related to reduced transaction costs [18]. However, there is a paucity of research at societal level [11]. The limited societal level studies claimed that sharing economy has become necessity for society as it allows community interaction, diverse choices and social connections $[19,29]$.

The social impacts of sharing economy are under explored in the existing literature. The literature calls for future research in this field [24]. Scholars are interested in examining innovations and entrepreneurial aspects of sharing economy leading to sustainable environment $[9,22,45]$. The sharing economy has potential to empower the society through micro-entrepreneurs. It has blurred the boundary of full-time employment and casual labour. The flexible work hours for suppliers, and detachment with a single organization is considered healthier for the society by letting the individuals to opt for multiple options of work according to their preference [21, 28]. However, these arrangements cannot offer employment benefits such as pension and health insurance. Absence of employment benefits and employees' rights lead to a major criticism of exploitation on sharing economy [36]. The non-provision of minimum wages is another concern of the sharing economy critics [14]. Although the scholars have highlighted the potential risks that may come with innovation of sharing economy, the available limited studies emphasise that gains/opportunities are greater than the potential drawbacks [27]. Further studies are still required to examine the social and economic implications of sharing economy digital platforms. This is because the sharing economy trend is though burgeoning; the research is in the early stages of research. The literature is limited and fragmented, which points the need of further research studies for theory building [7]. 


\subsection{Information Systems and Social Inclusion/Exclusion}

Social inclusion is a concept related to reducing inequalities and deprivation between the disadvantage groups and rest of the society by providing support and services to close the opportunity gap. It operates at multiple levels including, individual, groups, communities, organizations and society $[1,15,48]$. Social inclusion and exclusions are multidimensional and complex concepts. The general understanding consider social inclusion as good and exclusion as bad thing [44]. The concepts have been developing from multiple academic disciplines and professional practices such as, sociology, political science, economics, social justices, psychology, law, and rehabilitation. It is a multifaceted concept and its assessment is mostly subjective and context dependent $[48,53]$. The social structures where actors exist should also be considered while exploring social inclusion. The initial concept of social exclusion was associated with poverty and lack of income that cause economic inequality in the society. However, the continuous theoretical development has expanded the concept by incorporating multiple capability perspectives such as, economic, social, cultural and political $[38,39]$. Thus, the term social exclusion includes an absence of any of the wide range of social, economic, cultural, symbolic, and personal capital [32].

The process of social inclusion/exclusion shifts different trajectory over time and is dependent on education, business practices, social prejudice, policies and geographic characteristics. Information technology plays its part to improve social inclusion of the disadvantage communities, where people can be engaged with the help of technology to address social exclusion [10, 50, 51]. However, many IS scholars criticize the idea that ICT helps in social inclusion and argue that in developing countries ICT contributes to further social marginalization and exclusion [3, 47]. The studies highlight new aspects of social exclusion that have emerged due to access to the technology, lack of skills, fear to use the technology and absence of personal motivation/interest $[8,23]$.

Few studies point out the existence of gender and generation differences while using technologies. Adams and Fitch [1] identify the possibilities of slight bias in using mobile technologies for female and old generation. It has been discussed in the literature that provision of technology is not solely sufficient to achieve the social inclusion through ICT[53]. Although the inclusion activities are more prominent in technology dominated societies, there is a need for more studies to examine social inclusion in conventional societies as the institutional change may be observed in traditional treatment of gender. The challenges of demographic and geographic disparities are also discussed in ICT research. The large population living in rural areas may not be able to access the technology that results in digital exclusion. The IS research is focused on two extremes: ICT is either portrayed as a tool of great social inclusion or exacerbating digital exclusion $[48,50]$.

\section{Methodology}

We adopted a qualitative case study approach to examine the sharing economy digital platforms of travel industry in Pakistan [42]. The qualitative research methods are 
suitable for in-depth investigation of the phenomenon and to explore the answers of 'how' questions for theory building [13]. We selected two platform-based ride hailing companies operating in Pakistan, 'Uber' and 'Careem', for our data collection. Both Uber and Careem are sharing economy business that use on-line booking platform to connect passengers to local drivers using their personal, non-commercial vehicles [2, 52]. Uber was officially launched in Pakistan in early 2016, whereas Careem started its operations in early 2015. Careem had captured the market share in Pakistan before Uber came. While Careem is trying to maintain its image as a reliable and quality transport service provider, Uber focuses on cost leadership by lowering its fare to the minimal.

The data was collected through informal chats, observation and semi-structured interviews with cab drivers, customers and employees of both companies [6]. To obtain the holistic understating of ground realities, the informal conversations of various lengths were initiated by project team with random drivers during numerous rides taken in routine over a period of more than six months (February to September 2018). We also consulted secondary data, available on internet, in the form of newspaper articles and press releases. Altogether 34 semi-structured interviews were conducted from company employees (4 interviews -1 female and three males), customers (14 - 8 females and 6 males) and drivers (16 interviews - all males). Except three interviews, all interviews were conducted in Urdu language, which were later transcribed and translated into English. The transcripts were read multiple times for thematic analysis [40]. The concepts of ICT and social inclusion/exclusions helped us to make sense of the data. The themes were finalized after extensive discussions within the project team.

\section{Findings}

In the sections to follow we present the results and analysis of our field data grouped in relation to the focus of this article, which is to explore the social and economic implications of sharing economy digital platforms in Pakistan.

\subsection{Social Implications: Culture of Trust, Family Confidence and Women Empowerment}

Pakistan has a collectivist culture. Family has a central place in the Pakistani society. The men are expected to be in the breadwinning role, and women are the homemakers. The social fabric is built and sustained around the notions of honour and izzat. The women are considered to be the izzat of the family on whom the male honor depends. Generally, the women were not allowed to traverse the public sphere alone. Though, this notion has changed in the cities and a burgeoning number of women are working in the public sphere as well. However, the public transport has remained a huge problem. The bus system in Pakistan was not very safe, comfortable and efficient until recently. The local cabs have always been considered unsafe for the women and especially young girls to travel alone.

In the present project from which this article has emerged, a substantial number of respondents explained the presence of ride-hailing digital platforms in Pakistan as a 
'blessing in disguise'. With the emergence of sharing economy in the travel sector, the development of culture of trust along the gendered lines has paved way for business platforms to flourish. As explained by the respondents: 'it was not acceptable for families to allow girls to travel alone. But now the families trust the Careem and Uber and they have accepted these for usage by women of the family.' $(R$ 17, Student)

A number of factors, however, contributed towards this development of trust culture by the families. Firstly, there are instances in which a male family member experienced these services and developed trust after establishing a positive experience. Secondly, subsequent to this, for example, trust was developed when recommendation for a particular service was made by a female relative: 'I was never comfortable to travel alone on public transport. About few months back I was to go at a place where I could not drive. So me and my sister were contemplating as to what to do? We discussed this situation with a cousin who shared her positive experiences of travelling through Careem. So we decided to go for it. We ordered Careem and afterwards felt happy about our decision: it was both time and money efficient unlike the local cab. The local cab drivers would always tell a higher fare to women, and try to do small talk on the way. Careem was free of all these hassles.' ( $R 1$, professional) Thirdly, the apps of these services have also helped in developing trust: 'There is a share tracker option in the app. With it, the family feels relaxed. What happens is I activate my account on my brothers mobile. All the time I am travelling, my journey appears in his mobile. With traditional cabs this was not an option' ( $R$ 2, student)

The culture of trust was found to be working parallel with the confidence of the family in these services. The confidence of the family revolved around the Careem and Uber drivers as different from the local taxi drivers. This difference was articulated in two contexts (a) personal virtues like educational status, polite demeanour, and non-argumentative nature, and (b) the degree of professionalism, such as, time efficiency: 'The Careem drivers are educated. When you sit in the car, you only need to say: 'set the journey in the map' and then the entire journey is spent peacefully. They don't talk unnecessarily as it happens with traditional cab drivers.' (R 19, professional)

Consequently, women empowerment emerged as a major key theme. First, the respondents explained exercising control by making informed decisions in terms of the choices made about the type of service and the kind of vehicle they wished to travel in. Coupled with it was the degree of control over their money, which made them feel more empowered: 'I have used both Uber and Careem. One is money efficient and the other is time efficient. If I am to go for shopping, I choose Uber and if I have time deadline, I prefer Careem. Now I am making independent decisions, which makes me feel more confident.' (R 13, professional)

Last, but not the least, the women empowerment appeared in the context of women's increased mobility. According to the respondents, their families' would now feel relaxed in letting them travel alone at distant locations from their own homes.

Overall, in the cities, where these services are functioning; a cultural acceptance for women travelling by themselves is created. This culture of trust and confidence, yielding to the positive social implications, itself has created a demand for business 
platform in the Pakistani market. We will now elaborate this in the next section in the context of economic implications of shared economy in Pakistan.

\subsection{Economic Implications: Self-entrepreneurship, Employment and the Social Location}

Pakistan is a developing country in the South Asian region. With a population over 200 million, and the ever escalating unemployment, the platform business within the local travel sector has offered huge opportunities for self-entrepreneurship: 'I am an educated man. I was unemployed. With Careem and Uber an opportunity for selfemployment came to me.' (R23, Careem driver)

Thus, the unemployed youth, who otherwise would experience economic marginalization, are brought forward by platform businesses as productive members of the society. Their economic inclusion makes them socially inclusive as well. For instance, they take pride in their work by describing themselves as someone who is doing handsome earnings. Moreover, the inherent incentives offered to the captains' offer a sense of satisfaction and work loyalty in this industry. In addition, the social environment of Pakistan is constructed in a manner that it motivates them to remain employed in this sector in particular.

In this research, the gender was found to be a starkly intertwined factor with the economic implications for these business platforms. The captains who were attached to these platforms for more than two years articulated this: 'Between 5:00pm to 6:00 pm, if you work as captain, you earn a lot. This is office closing time. Generally, women are the clients, as they are seeking for safe journey.' (R18, Careem driver)

Another important pull described by the captains is the vast geographical distance within the city: 'What happen is that certain areas are lucrative if we reach their early morning. If I am at Bahria early in the morning, the passenger generally goes to Blue Area, where all the offices are situated. From there, whoever goes out will ask to take them to an office located in another part of the city. There is shortage of supply before the office timings. So I always make my supply there' (R20, Careem driver)

Respondents also spoke about the wider employment opportunities in platform business. Firstly, those who do not have their own vehicle can also be employed: 'Those people who are unemployed can go to Careem office to acquire the list of people giving their cars to Careem. Once a mutual agreement between the car owner and potential captain is settled, you are employed on a monthly salary.' (R8, Careem driver)

Secondly, the people who are part of platform business in Pakistan are optimistic about future possible economic opportunities through expansion in the base of ridehailing travel sector. According to few of the respondents, they envisage a demand for travel business platform from the customers end. This, in turn, would compel a continued supply of hiring more captains and creating more employment opportunities.

Thirdly, the expansion of business platform in Pakistan is explained by respondents in the context of diversified businesses: 'Careem is about to launch CareemFood and 
CareemPay in Pakistan. Both of these domains will work like JazzCash for example. That is not earning through the core business 'transport'. (R11, Careem driver)

As noted in these quotes, the existing business platforms are viewed as having a huge potential in the Pakistani market. It is pertinent to mention that the economics alone is not the sufficient reason for illustrating these dynamics. In addition, the social location emerged as a major key theme central to the daily experiences of people associated with business platforms. Social location, in the context of this study was described mainly at the end of business platform self-entrepreneurs. Their explanation was rooted within their experiences of heighted social status, education, the class affiliation of their clients, and the geographical location at which they felt privileged to work. The heightened social status was described in the context of captains' becoming part of the global service sector. They viewed themselves as 'vendors' and not as local cab drivers, who according to them belonged to lower strata of the society, and mostly did not have their own vehicles: 'You see we are not ordinary cab drivers, who misbehave, smoke cigarettes while at work. We are professionals working as 'vendors' in the international market.' (R10, Careem driver)

Education was further described as another personal trait to describe their social status. The respondents, who were captains used their educated status to establish a point of departure from the local taxi drivers: 'I am educated, and so are the others, who are working in this industry. Our way of talking on phone with the client or when he/she is in the car is different from the local taxi driver, whose dressing, speech, mannerism; everything is like an illiterate menial worker.' (R11, Careem driver)

Another respondent also articulated this: 'I am a computer technician. I wanted to buy a new car. But the lease was high. It's from there that the idea came to my mind that working through apps would not be difficult, so let's try Uber.' (R19, Careem driver) The personal circumstances coupled with education are the key factor in describing their social location as distinct and different from the local taxi drivers. This was further articulated by respondents in conjunction with the class affiliation of their clients: 'Our clients respect us. They are educated people. They also know that like them we are also educated and this work is only to earn additional money.' (R16, Uber driver)

\subsection{Contradictions and Exclusions}

Social and economic implications in the form of inclusionary practices were not the only contexts in which respondents described their experiences of the shared economy in Pakistan. Echoing Frederic et al (2009) genuine concern of the information technologies bringing challenges, the exclusionary impulses and the shifting realities, were also voiced by the respondents in this study [8, 23]. Contrast to the prestige, social status and economic benefits that are reflected above, the respondents also pointed certain contradictions. First, they showed concerns about social acceptance by the society. Back home in the villages from where they hailed to the cities, they did not want the word about them working as 'captains' to float: 'My immediate family knows that I am an Uber captain. They feel proud to see my good earnings. But we have not disclosed it to our relatives in the village. You see, they see me as a relative doing office job which is my day-time work. If they find out about this Uber 
work, they would gossip. They would not understand that I am part of the global services sector and also a professional in this field.' (R4, Uber driver)

Secondly, the contradictions were also expressed in relation to tampering with the client supportive mechanisms. One such mechanism was the inherent feature of giving stars to the captain, which also served the function of ensuring that the captain would not misbehave. However what if he does so? An exception to the all-parsing scenarios was: 'As captains we depend upon stars to receive additional bonus. I know drivers, who misbehaved, and their Uber contract got cancelled. But were on road again as they registered with another SIM.' (R7, Uber driver)

Exclusions turned out to be another key sub-theme. The marginalized populations, such as the elderly, the illiterate and rural populations are found to be excluded: ' $M y$ elderly parents don't know how to use mobile phone. They depend on me to book a ride for them' (R3, student)

'I have been a taxi driver all my life. People say uncle go for Uber, you will earn good. But I am illiterate and cannot use mobile phone.' (R24, Local cab driver)

'In cities, it's fine to use Careem. But in my village, people would not accept for a single girl to be sitting in a car with a stranger.' (R13, professional)

\section{Discussion and Conclusion}

This study contributes to the emerging literature of sharing economy [24]. It explores the interaction of different users group (producers and consumers) and examine the impacts of sharing economy digital businesses at societal level [19, 29].

The answer to the first question - "How are digital ride-hailing companies transforming the existing social and economic structures? - lies particularly in the context of changing the social and economic landscape of cities in Pakistan. The two ride-hailing travel businesses that are part of sharing economy include Careem and Uber. At the societal front, with the advent of these services, a cultural shift in the form of allowing young women to travel by themselves has emerged. This has become possible through the emergence of changing dynamics: culture of trust and family confidence in business platforms has developed due to their inherent feature of offering travel services that reduce harassment, availability at doorstep, and visibility of travel vehicle throughout the journey. This in turn has resulted in the women empowerment at two levels. First, the women in Pakistan are experiencing making their own decisions about opting for a particular service. Second, the women's mobility has increased as they are able to traverse multiple spaces in a day. However, considering different incidents of harassment during travel reported in media both in developed and developing countries, there is a dire need to the examine other side of the coin.

In addressing the second question - "How can sharing economy contribute in social inclusion/exclusion in the society." - We found there were a number of inclusionary steps that these platform businesses made possible to happen in Pakistan. Firstly, Pakistan has a huge issue of unemployed population. The ride-hailing service sector has offered these people to be employed either full-time or part-time. This has 
converted them into productive members of the society. Thus, the innovations and entrepreneurial aspects of sharing economy are required to be explored further for sustainable development [22, 45].

Secondly, the economic stability has given them social stability as well. They are able to move in the society as a hardworking person, who is able to support himself and his family well. There are a number of challenges as well such as the key fact of excluding certain marginalized populations. The elderly, young girls living in the rural areas and illiterate people are unable to become part of this global service sector, and therefore are at the cross roads of being further pushed to the periphery. The nascent literature highlights some experiences where platforms may promote inequality and unhealthy labour conditions [37]. Our findings also report that the absence of regulations and control mechanisms may lead to the possibilities of inequality in the society [41]. The critics of sharing economy call it as a rentier capitalism promoting consumerism for wealthy people who possess the assets [43]. With all these contradictions, exclusions and challenging encounters, the key point still remains, that is shared economy digital platforms have become a pertinent and prominent part of Pakistan's economy and culture. The wheels of growth are spinning in the travel industry of platform businesses. Now there is an increasing need to not only focus on positive experiences, but also handling the negative consequences of it in society.

In this article, we try to bring IS scholars' attention toward exploring social, organisational and technological dimensions of sharing economy business models and digital platforms. It is a right time to shift the focus from economic benefits of sharing economy to societal and organisational aspects [28]. This initial level research also identifies the need of future research on digital platforms from other industries in different research context.

\section{References}

1. Adams, C., Fitch, T.: Social Inclusion and the Shifting Role of Technology: Is Age the New Gender in Mobile Access? Social Inclusion: Societal and Organizational Implications for Information Systems, pp. 203-215. Springer (2006)

2. Amit, R., Han, X.: Value creation through novel resource configurations in a digitally enabled world. Strategic Entrepreneurship Journal 11, 228-242 (2017)

3. Armstrong, D.J., Riemenschneider, C.K., Giddens, L.G.: The advancement and persistence of women in the information technology profession: An extension of Ahuja's gendered theory of IT career stages. Information Systems Journal (2018)

4. Ballús-Armet, I., Shaheen, S.A., Clonts, K., Weinzimmer, D.: Peer-to-peer carsharing: Exploring public perception and market characteristics in the San Francisco Bay area, California. Transportation Research Record 2416, 27-36 (2014)

5. Botsman, R., Rogers, R.: What's mine is yours: how collaborative consumption is changing the way we live. (2011)

6. Cassell, C., Symon, G.: Essential guide to qualitative methods in organizational research. Sage Publications Ltd, UK (2004) 
7. Cheng, M.: Sharing economy: A review and agenda for future research. International Journal of Hospitality Management 57, 60-70 (2016)

8. Choudrie, J., Ghinea, G., Songonuga, V.N.: Silver surfers, e-government and the digital divide: An exploratory study of UK local authority websites and older citizens. Interacting with Computers 25, 417-442 (2013)

9. Cohen, B., Kietzmann, J.: Ride on! Mobility business models for the sharing economy. Organization \& Environment 27, 279-296 (2014)

10.Cushman, M., McLean, R.: Exclusion, inclusion and changing the face of information systems research. Information Technology \& People 21, 213-221 (2008)

11.Dreyer, B., Lüdeke-Freund, F., Hamann, R., Faccer, K.: Upsides and downsides of the sharing economy: Collaborative consumption business models' stakeholder value impacts and their relationship to context. Technological Forecasting and Social Change 125, 87-104 (2017) 12.Economist, T.: The rise of the sharing economy. The Economist 9, (2013)

13.Eisenhardt, K.M.: Building theories from case study research. Academy of Management Review 14, 532-550 (1989)

14.Gobble, M.M.: Regulating innovation in the new economy. Research-Technology Management 58, 62-67 (2015)

15.Gurstein, M.: Community informatics: Enabling community uses of information and communications technology. Community informatics: Enabling communities with information and communications technologies, pp. 1-30. IGI Global (2000)

16.Guttentag, D.: Airbnb: disruptive innovation and the rise of an informal tourism accommodation sector. Current issues in Tourism 18, 1192-1217 (2015)

17.Hamari, J., Sjöklint, M., Ukkonen, A.: The sharing economy: Why people participate in collaborative consumption. Journal of the association for information science and technology 67, 2047-2059 (2016)

18.Hansen Henten, A., Maria Windekilde, I.: Transaction costs and the sharing economy. info 18, $1-15$ (2016)

19.Hwang, J., Griffiths, M.A.: Share more, drive less: Millennials value perception and behavioral intent in using collaborative consumption services. Journal of Consumer Marketing 34, 132-146 (2017)

20.Kathan, W., Matzler, K., Veider, V.: The sharing economy: Your business model's friend or foe? Business Horizons 59, 663-672 (2016)

21.Kessler, A.: Brian Chesky: The 'sharing economy'and its enemies. The Wall Street Journal (2014)

22.Kostakis, V., Bauwens, M.: Network society and future scenarios for a collaborative economy. Springer (2014)

23.Lee, E., Han, S., Chung, Y.: Internet use of consumers aged 40 and over: Factors that influence full adoption. Social Behavior and Personality: an international journal 42, 1563-1574 (2014)

24.Lee, Z.W., Chan, T.K., Balaji, M., Chong, A.Y.-L.: Why people participate in the sharing economy: an empirical investigation of Uber. Internet Research 28, 829-850 (2018)

25.Leismann, K., Schmitt, M., Rohn, H., Baedeker, C.: Collaborative consumption: towards a resource-saving consumption culture. Resources 2, 184-203 (2013)

26.Lessig, L.: Remix: Making art and commerce thrive in the hybrid economy. Penguin (2008) 
27.Malhotra, A., Van Alstyne, M.: The dark side of the sharing economy... and how to lighten it. Communications of the ACM 57, 24-27 (2014)

28.Martin, C.J.: The sharing economy: A pathway to sustainability or a nightmarish form of neoliberal capitalism? Ecological economics 121, 149-159 (2016)

29.McArthur, E.: Many-to-many exchange without money: why people share their resources. Consumption Markets \& Culture 18, 239-256 (2015)

30.Möhlmann, M.: Collaborative consumption: determinants of satisfaction and the likelihood of using a sharing economy option again. Journal of Consumer Behaviour 14, 193-207 (2015)

31.Nica, E., Potcovaru, A.-M.: The social sustainability of the sharing economy. Economics, Management and Financial Markets 10, 69 (2015)

32.O'Reilly, D.: Social inclusion: A philosophical anthropology. Politics 25, 80-88 (2005)

33.Parker, G.G., Van Alstyne, M.W., Choudary, S.P.: Platform Revolution: How Networked Markets Are Transforming the Economy and How to Make Them Work for You. WW Norton \& Company (2016)

34.Puschmann, T., Alt, R.: Sharing economy. Business \& Information Systems Engineering 58, 93-99 (2016)

35.PwC: The sharing economy: how is it affecting you and your business? . PricewaterhouseCoopers (2015)

36.Richardson, L.: Performing the sharing economy. Geoforum 67, 121-129 (2015)

37.Schor, J.B., Fitzmaurice, C.J.: Collaborating and connecting: the emergence of the sharing economy. Handbook of research on sustainable consumption 410, (2015)

38.Sen, A.: Development as freedom. Oxford University Press, NY, USA (1999)

39.Sen, A.K.: The idea of justice. Harvard University Press, USA (2009)

40.Silverman, D.: Interpreting qualitative data: Methods for analyzing talk, text and interaction. Sage Publications Ltd, UK (2006)

41.Slee, T.: What's yours is mine: Against the Sharing Economy. Or Books (2017)

42.Stake, R.E.: The art of case study research. Sage Publications Ltd, Thousand Oaks, USA (1995)

43.Standing, G.: The corruption of capitalism: Why rentiers thrive and work does not pay. Biteback Publishing (2016)

44.Stewart, F.: Groups and capabilities. Journal of human development 6, 185-204 (2005)

45.Sundararajan, A.: From Zipcar to the sharing economy. Harvard Business Review 1, (2013)

46.Sundararajan, A.: The sharing economy: The end of employment and the rise of crowdbased capitalism. Mit Press (2016)

47.Tambulasi, R.I.: Pushed to the abyss of exclusion: ICT and social exclusion in developing countries. Journal of Information, Communication and Ethics in Society 7, 119-127 (2009)

48.Trauth, E., Howcroft, D., Butler, T., Fitzgerald, B., DeGross, J.: Social Inclusion: Societal and Organizational Implications for Information Systems: IFIP TC8 WG 8.2 International Working Conference, July 12-15, 2006, Limerick, Ireland. Springer (2006)

49.Trauth, E., Joshi, K.D., Kvasny, L.: ISJ Editorial - Special issue of Information Systems journal on Social Inclusion. Information Systems Journal 28, 989-994 (2018)

50.Urquhart, C., Underhill-Sem, Y.: Special issue on "ICTs and social inclusion”. Journal of Information, Communication and Ethics in Society 7, (2009)

51.Van Winden, W.: The end of social exclusion? On information technology policy as a key to social inclusion in large European cities. Regional Studies 35, 861-877 (2001) 
52.Voege, T.: Data-Led Governance of Self-driving Vehicles for Urban Shared Mobility. The Governance of Smart Transportation Systems, pp. 81-101. Springer (2019)

53.Warschauer, M.: Technology and social inclusion: Rethinking the digital divide. MIT press (2004) 